\title{
Perinatal outcome in relation to maternal glycaemic control in gestational diabetes mellitus
}

\author{
Kanmani K. ${ }^{1}$, Sudha Subramanian ${ }^{2 *}$ \\ Department of Obstetrics and Gynecology, ISO and KGH, Chennai, Tamil Nadu, India \\ Received: 09 August 2017 \\ Accepted: 04 September 2017 \\ *Correspondence: \\ Dr. Sudha Subramanian, \\ E-mail: sudhammc@gmail.com \\ Copyright: $\odot$ the author(s), publisher and licensee Medip Academy. This is an open-access article distributed under \\ the terms of the Creative Commons Attribution Non-Commercial License, which permits unrestricted non-commercial \\ use, distribution, and reproduction in any medium, provided the original work is properly cited.
}

\begin{abstract}
Background: Early diagnosis and treatment of gestational diabetes with adequate antenatal care are essential to reduce the adverse neonatal outcomes.

Methods: All selected women were subjected to a detailed history taking comprising of age, parity, prepregnant body weight, medication history, family history, medical history, detailed obstetric history. Then they were subjected to clinical examination and routine laboratory investigations. Antenatal women were diagnosed with GDM, when 75gm GCT $\geq 140 \mathrm{mg} / \mathrm{dl}$ based on DIPSI criteria. Fasting and postprandial blood sugars (2hours) were done and if FBS and PPBS were normal, the patient was labelled as GDM on meal plan. If fasting $>96 \mathrm{mg} / \mathrm{dl}$ and 2-hr postprandial blood sugar $>121 \mathrm{mg} / \mathrm{dl}$, Inj.insulin was started. Patients were managed according to the FBS and PPBS values throughout antenatal period and the perinatal outcomes were studied.

Results: Among 150 patients, multiparous women constitute $65.3 \%$ and primi $34.7 \% .60 \%$ of the patients were in age group of 26 to 30 years.59.3\% of patients were in BMI of range 25 to 30.Family history of diabetes was present in $24.7 \%$ of the patients. Previous history of GDM was present in $27.3 \%$ of cases. $98 \%$ of GDM were detected in $2^{\text {nd }}$ trimester. The percentage of cases presented with macrosomia was $8.7 \%$, RDS $3.3 \%$, hypoglycaemia $6 \%$, hyperbilirubinemia $3.3 \%$, IUD $0.7 \%$, perinatal injury $1.3 \%$, NICU admission requiring $\geq 3$ days of admission was $12 \%$.
\end{abstract}

Conclusions: There is association of elevated FBS and PPBS values with occurrence of adverse perinatal outcome.

Keywords: Adverse perinatal outcomes, Blood sugar, Gestational diabetes

\section{INTRODUCTION}

Gestational diabetes mellitus is defined as carbohydrate intolerance of variable severity resulting in hyperglycaemia with the onset or first recognition during pregnancy. ${ }^{1}$ This is applicable regardless of the patient whether they are on insulin or only on diet modification.

GDM represents an unidentified pre-existing disease or because of the stress in pregnancy leading to a compensated metabolic abnormality which is unmasked or a direct consequence leading to altered maternal metabolism in pregnancy. GDM is associated with increased incidence of adverse maternal outcome such as preeclampsia, gestational hypertension, polyhydramnios, preterm labour and increased caesarean section rate and higher risk of type-2 diabetes in their later life in future. ${ }^{2}$

Babies born to mothers with gestational diabetes mellitus have increased risk for macrosomia, hypoglycaemia, respiratory distress, still birth, hypocalcaemia, shoulder dystocia, seizures, hyperbilirubinemia, intrauterine death, perinatal morbidity. Women with adequate blood glucose control can decrease the risk of adverse neonatal outcomes when gestational diabetes is treated effectively. 
These offspring are more prone for developing obesity in childhood and type-2 diabetes in their later life. . $^{3,4}$

Aims and objectives of present study were to determine perinatal outcome in relation to maternal fasting and postprandial ( 2 hours) blood sugar control in gestational diabetes mellitus and tp study Perinatal outcomes which included macrosomia, Respiratory distress syndrome, hypoglycaemia, seizures, hyperbilirubinemia, NICU admission, Anomaly, IUD, Stillbirth, perinatal injury, perinatal mortality.

\section{METHODS}

The study was conducted at the Institute of Social Obstetrics, Government Kasturiba Gandhi Hospital, Chennai. This was prospective study. The study was conducted for a period of one year from July 2016 to July 2017. The study group consisted of 150 patients after considering the exclusion and inclusion criteria.

\section{Inclusion criteria}

- $\quad$ Singleton pregnancy

- $\quad$ Age $>18$ and $<35$ years

- GDM mothers on meal plan and insulin

- Cephalic presentation

\section{Exclusion criteria}

- Overt diabetes.

- Abnormal presentation.

- Preterm and PROM.

- Medical disorders like hypothyroidism and hypertension.

- Multiple pregnancy and IUGR.

\section{Method of study}

All antenatal mothers attending the OPD were subjected to $75 \mathrm{gm}$. of glucose challenge test in first, second and third trimester. If GCT was elevated above $140 \mathrm{mg} / \mathrm{dl}$, these patients were diagnosed as GDM as per DIPSI criteria and were advised meal plan for 2 weeks. Fasting and postprandial blood sugars ( 2 hours) were done. ${ }^{5}$

If FBS and PPBS were normal, the patient was labelled as GDM on meal plan. If fasting $>96 \mathrm{mg} / \mathrm{dl}$ and $2-\mathrm{hr}$ postprandial blood sugar $>121 \mathrm{mg} / \mathrm{dl}$, insulin is started along with diet modification and patient is labeled as GDM on insulin. ${ }^{6}$

In patients with GDM on insulin FBS and PPBS were taken according to the blood sugar control and the dose of insulin was adjusted. In case of GDM on meal plan, FBS and PPBS were taken every 15 days.
If the GCT was normal is $1^{\text {st }}$ trimester, it was repeated again in $2^{\text {nd }}$ trimester at 24 weeks and $3^{\text {rd }}$ trimester in 32 weeks. If it was normal in $2^{\text {nd }}$ trimester, it was again done in $3^{\text {rd }}$ trimester. $^{7}$

Follow up the patients were done with fasting and postprandial blood sugar values and the dose of insulin was adjusted according to the blood sugar values.

The patient was then followed up and following perinatal outcomes macrosomia, hypoglycaemia, respiratory distress syndrome, seizures, hyperbilirubinemia, anomaly, stillbirth, IUD, perinatal morbidity and mortality were studied.

\section{RESULTS}

Among the total 150 patients, 63 patients were on meal plan, 79 patients were on insulin, 6 patients initially on meal plan were converted to insulin and 2 patients initially on insulin were converted to meal plan (Table 1).

Table 1: Distribution of cases according to treatment of GDM.

\begin{tabular}{|lll|}
\hline GDM & No. of patients & $\%$ \\
\hline Meal plan & 63 & 42.0 \\
\hline Insulin with meal plan & 79 & 52.7 \\
\hline Meal plan converted to insulin & 6 & 4.0 \\
\hline Insulin converted to insulin & 2 & 1.3 \\
\hline Total & 150 & 100 \\
\hline
\end{tabular}

In present study, $82.7 \%$ patients were $>25$ years and $14.7 \%$ of the patients had BMI $>30$. Since $\mathrm{p}$ value $<0.05$, it was concluded that there were significant association between age and BMI with GDM since $\mathrm{p}$ value $<0.05$.

Multiparous women $(65.3 \%)$ were more affected than primigravida $(34.7 \%)$. Since $\mathrm{p}>0.05$, there was no significant association between parity and occurrence of GDM.

In a study by Catherin et al family history of diabetes were present in $35 \%$ of cases. ${ }^{8}$ In present study family history was present in $24.7 \%$ of cases. Since $p$ value is $<0.05$, there was a significant association between family history of diabetes and the occurrence of GDM in pregnancy. In a study by Catherin et al history of GDM in previous pregnancy was associated with occurrence of GDM in present pregnancy. ${ }^{8}$

In present study, previous history of GDM was present in $27.3 \%$ of cases. There was a significant association between previous GDM histories with onset of GDM since $\mathrm{p}<0.05$. In study by Yogev et al the incidence of preeclampsia in GDM with good glycaemic control was $7.8 \%$ in present study it was $8.7 \%$ of cases. $^{9}$ 
Table 2: Association of risk factors with GDM.

\begin{tabular}{|c|c|c|c|c|c|c|c|}
\hline \multirow{2}{*}{$\begin{array}{l}\text { No. of risk } \\
\text { factors }\end{array}$} & & \multicolumn{5}{|c|}{ GDM on treatment } & \multirow[t]{2}{*}{ P value } \\
\hline & & Meal plan & $\begin{array}{l}\text { Insulin and } \\
\text { meal plan }\end{array}$ & $\begin{array}{l}\text { Meal plan to } \\
\text { insulin }\end{array}$ & $\begin{array}{l}\text { Insulin to } \\
\text { meal plan }\end{array}$ & Total & \\
\hline \multirow{2}{*}{0} & No. & 17 & 4 & 1 & 0 & 22 & \multirow{14}{*}{0.0001} \\
\hline & $\%$ & 77.3 & 18.2 & 4.5 & 0 & & \\
\hline \multirow{2}{*}{1} & No. & 42 & 29 & 1 & 2 & 74 & \\
\hline & $\%$ & 56.8 & 39.2 & 1.4 & 2.7 & & \\
\hline \multirow{2}{*}{2} & No. & 4 & 20 & 1 & 0 & 25 & \\
\hline & $\%$ & 16 & 80 & 4 & 0 & & \\
\hline \multirow{2}{*}{3} & No. & 0 & 8 & 2 & 0 & 10 & \\
\hline & $\%$ & 0 & 80 & 20 & 0 & & \\
\hline \multirow{2}{*}{4} & No. & 0 & 11 & 1 & 0 & 12 & \\
\hline & $\%$ & 0 & 91.7 & 8.3 & 0 & & \\
\hline \multirow{2}{*}{5} & No. & 0 & 7 & 0 & 0 & 7 & \\
\hline & $\%$ & 0 & 100 & 0 & 0 & & \\
\hline \multirow{2}{*}{ Total } & No. & 63 & 79 & 6 & 2 & 150 & \\
\hline & $\%$ & 42 & 52.7 & 4.0 & 1.3 & & \\
\hline
\end{tabular}

$\mathrm{P}<0.05$. There was a significant association between numbers of risk factors (Age $>25$ years, BMI $>30$, family history of diabetes, previous GDM, gestational hypertension) and the occurrence of GDM.

There was a significant association between number of risk factors and the occurrence of GDM (Table 2). But there was no significant association between the number of risk factors and the occurrence of adverse neonatal outcomes.
GDM screening should be started in first trimester. ${ }^{10}$ Early detection and blood sugar control results in better foetal outcome. In present study $98 \%$ cases were detected in $2^{\text {nd }}$ trimester, $0.7 \%$ and $1.3 \%$ of cases were detected in $1^{\text {st }}$ trimester and $3^{\text {rd }}$ trimester respectively (Table 3 ).

Table 3: Diagnosis of GDM at each trimester.

\begin{tabular}{|lll|}
\hline Diagnosis & No. of patients & $\%$ \\
\hline $1^{\text {st }}$ trimester & 1 & 0.7 \\
\hline $2^{\text {nd }}$ trimester & 147 & 98.0 \\
\hline $3^{\text {rd }}$ trimester & 2 & 1.3 \\
\hline Total & 150 & 100.0 \\
\hline
\end{tabular}

$98 \%$ of GDM were detected in $2^{\text {nd }}$ trimester.

Evers et al gives $44 \%$ of operative delivery, Yogev et al gives $30 \%$ of operative delivery, in the present study the percentage of patients who had caesarean section was $42 \%$ (both LSCS and repeat LSCS), the most common indication being Previous LSCS (46\%) and CPD $(22.2 \%){ }^{9,11}$

\section{Perinatal outcomes}

Jacques et al found the incidence of NICU admission was $16 \%$, respiratory distress syndrome was $6.9 \%$, hypoglycaemia $3.2 \%$. Evers et al found the incidence of respiratory distress syndrome to be $15 \%$, hyperbilirubinemia as $25 \%$, macrosomia as $45 \% .{ }^{11}$ In study by Casson et al the incidence of stillbirth was $2.5 \%$. A study by Priyanka et al showed the incidence of macrosomia was $18 \%$, NICU admission $27.2 \%$, hypoglycaemia $9 \%$, hyperbilirubinemia $12 \% .{ }^{12}$ In a study by Preeti et al showed the incidence of respiratory distress syndrome was $3.23 \%$, perinatal injury was $1.4 \%$, macrosomia was $7 \%$.

In the present study the incidence of macrosomia was $8.7 \%$, RDS $3.3 \%$, hypoglycaemia $6 \%$, hyperbilirubinemia $3.3 \%$, IUD $0.7 \%$, perinatal injury $1.3 \%$, NICU admission requiring more than 3 days of admission was $12 \%$. 
$\mathrm{P}<0.05$, there was a significant association between GDM and the occurrence of macrosomia, hypoglycaemia and NICU admission $\geq 3$ days in neonates.

$\mathrm{P}>0.05$, there was no significant association between GDM and the occurrence of RDS, hyperbilirubinemia, IUD, perinatal morbidity (Table 4). There were no cases of seizures (due to hypoglycaemia or hypocalcaemia), still birth, anomaly, perinatal mortality.

It was evident that, as the fasting blood sugar, postprandial sugar increases, percentage of adverse neonatal outcome increases (Table 5, 6). Since $\mathrm{p}<0.05$, there was significant association between FBS, PPBS and the occurrence of adverse neonatal outcomes.

Table 4: Occurrence of adverse neonatal outcomes.

\begin{tabular}{|c|c|c|c|c|c|c|c|}
\hline \multirow{2}{*}{$\begin{array}{l}\text { Adverse neonatal } \\
\text { outcomes }\end{array}$} & \multicolumn{5}{|c|}{ GDM on treatment } & \multirow[t]{2}{*}{ Total } & \multirow[t]{2}{*}{ P Value } \\
\hline & & Meal plan & $\begin{array}{l}\text { Insulin and } \\
\text { meal plan }\end{array}$ & $\begin{array}{l}\text { Meal plan to } \\
\text { insulin }\end{array}$ & $\begin{array}{l}\text { Insulin to } \\
\text { meal plan }\end{array}$ & & \\
\hline \multirow{2}{*}{ Macrosomia } & No. & 0 & 13 & 0 & 0 & 13 & \multirow{2}{*}{0.005} \\
\hline & $\%$ & 0 & 100 & 0 & 0 & & \\
\hline \multirow{2}{*}{ RDS } & No. & 0 & 5 & 0 & 0 & 5 & \multirow{2}{*}{0.199} \\
\hline & $\%$ & 0 & 100 & 0 & 0 & & \\
\hline \multirow{2}{*}{ Hypoglycaemia } & No. & 0 & 9 & 0 & 0 & 9 & \multirow[b]{2}{*}{0.035} \\
\hline & $\%$ & 0 & 100 & 0 & 0 & & \\
\hline \multirow{2}{*}{ Hyperbilirubinemia } & No. & 0 & 5 & 0 & 0 & 5 & \multirow[b]{2}{*}{0.199} \\
\hline & $\%$ & 0 & 100 & 0 & 0 & & \\
\hline \multirow{2}{*}{ IUD } & No. & 0 & 1 & 0 & 0 & 1 & \multirow{2}{*}{0.824} \\
\hline & $\%$ & 0 & 100 & 0 & 0 & & \\
\hline \multirow{2}{*}{ Perinatal morbidity } & No. & 0 & 2 & 0 & 0 & 2 & \multirow{2}{*}{0.610} \\
\hline & $\%$ & 0 & 100 & 0 & 0 & & \\
\hline \multirow{2}{*}{$\begin{array}{l}\text { NICU Admission } \\
\geq 3 \text { days }\end{array}$} & No. & 1 & 17 & 0 & 0 & 18 & \multirow{2}{*}{0.002} \\
\hline & $\%$ & 5.6 & 94.4 & 0 & 0 & & \\
\hline
\end{tabular}

$\mathrm{P}<0.05$, there was a significant association between GDM and the occurrence of macrosomia, hypoglycaemia and NICU admission $\geq 3$ days in neonates; P>0.05, there was no significant association between GDM and the occurrence of RDS, hyperbilirubinemia, IUD, perinatal morbidity.

Table 5: Association of FBS and adverse neonatal outcomes.

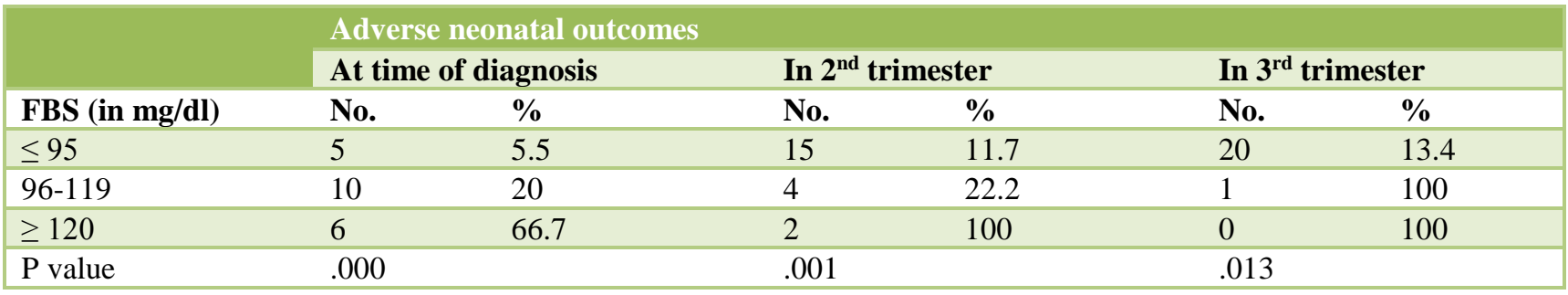

$\mathrm{P}<0.05$, there was a significant association between FBS and the occurrence of adverse neonatal outcomes.

Table 6: Association of PPBS and adverse neonatal outcomes.

\begin{tabular}{|c|c|c|c|c|c|c|}
\hline \multirow{3}{*}{ PPBS (in mg/dl) } & \multicolumn{6}{|c|}{ Adverse neonatal outcomes } \\
\hline & \multicolumn{2}{|c|}{ At time of diagnosis } & \multicolumn{2}{|c|}{ In $2^{\text {nd }}$ trimester } & \multicolumn{2}{|c|}{ In $3^{\text {rd }}$ trimester } \\
\hline & No. & Percent & No. & Percent & No. & Percent \\
\hline$<120$ & 4 & 5.8 & 5 & 7.7 & 6 & 5.5 \\
\hline $121-159$ & 2 & 7.7 & 5 & 9.8 & 12 & 33.3 \\
\hline $160-199$ & 12 & 23.1 & 10 & 32.3 & 3 & 60 \\
\hline$\geq 200$ & 3 & 100 & 1 & 100 & 0 & 100 \\
\hline $\mathrm{P}$ value & .000 & & 0.001 & & 0.00 & \\
\hline
\end{tabular}

$\mathrm{P}<0.05$, there was a significant association between PPBS and the occurrence of adverse neonatal outcomes 


\section{DISCUSSION}

For universal screening Seshiah et al suggested that a single glucose challenge test with $75 \mathrm{gm}$ of oral glucose load and when 2 hour plasma venous sample is $\geq 140$ $\mathrm{mg} / \mathrm{dl}$, it is diagnosed to have GDM. ${ }^{13}$ This method is recommended by WHO, because of single step procedure and it is used for both screening as well as diagnostic test.

Foetus of diabetic mothers have wide range of structural and biochemical abnormalities that can be reduced or eliminated by improving the control of blood sugar metabolism.

\section{Macrosomia}

Neonate weighing more than $4.5 \mathrm{~kg}$. In Indian consensus new-born $\geq 4 \mathrm{Kg}$ is considered as macrosomia. Pederson's hypothesis states that increased maternal blood glucose results in increased foetal blood glucose levels which in turn stimulates the pancreatic foetal cells to produce large amount of insulin which is one of the main growth factor for foetal tissue (Pedersen). ${ }^{14}$ Insulin has growthpromoting effects by diverting the cell metabolism into anabolic process like lipogenesis, glucogenesis and protein synthesis.

There is a continuous association of maternal blood glucose level with increased birth weight of baby. The incidence of macrosomia is decreased when blood sugar is under control. ${ }^{15}$ The incidence of shoulder dystocia, birth injuries, neonatal morbidity and asphyxia are increased in macrosomic babies. ${ }^{16}$ The risk of birth trauma is more in infants weighing $\geq 4.5 \mathrm{~kg} .{ }^{17}$ Women with elevated fasting and normal postprandial blood sugar values are having the infants at increased risk of macrosomia.

\section{Hypoglycemia}

Due to endogenous hyperinsulinemia and suppression of endogenous glucose production, the infants are at increased risk of hypoglycaemia at 1-3 hours of birth. ${ }^{18}$ Neonatal hypoglycaemia is due to hyperplasia of pancreatic beta cells of the foetus and the increased maternal substrate delivery to the foetus as proposed by Pederson et al. ${ }^{14}$ After birth, glucose which is supplied continuously from the mother is stopped, so neonate is more prone to develop hypoglycaemia due to insufficient delivery of the substrate. Perinatal stress due to release of catecholamine and depletion of glycogen makes the neonates for further development of hypoglycaemia.

$50 \%$ of babies are asymptomatic. Symptoms of hypoglycaemia include irritability, jitteriness, high pitched or weak cry, apathy, poor feeding, hypotonia or seizures. Hypoglycaemia that requires intervention may be persisted for one week or longer resulting in increased neonatal intensive care admission and prolonged hospital stay in neonates. ${ }^{19}$
The incidence of hypoglycaemia is high in infants whose mothers had a longer duration of diabetes. ${ }^{20}$ Hypoglycaemia is defined as when blood sugar level is lower than $45 \mathrm{mg} / \mathrm{dl}$ but the precise level remain controversial. Threshold levels was proposed by Cornblath et al. ${ }^{21}$

\section{Hypocalcemia}

Defined as serum calcium $<7.5 \mathrm{mg} / \mathrm{dl} .{ }^{22}$ Asphyxia and prematurity increases the level of cortisol which is a vitamin $\mathrm{D}$ antagonist at the intestinal level. Respiratory distress and foetal metabolic acidosis results in shifting of calcium from intracellular to extracellular pool and the reversal occurs during the correction of acidosis causing hypocalcaemia. Hypocalcaemia is also associated with delay in parathyroid hormone synthesis after birth. Symptoms include jitteriness or seizure activity. ${ }^{23,24}$ True hypocalcaemia is very rare. In most cases, symptoms caused due to lower level of calcium are mainly due to low blood glucose levels.

\section{Respiratory distress syndrome}

Insulin antagonizes the stimulatory effects of cortisol on fibroblast to induce the synthesis of fibroblast pneumocyte factor. This inhibits phosphotidyl choline production on type 2 pneumocyte cells. RDS presents after the birth shortly and manifested as tachypnea, chest wall retractions, tachycardia, grunting and nasal flaring and may have cyanosis. Most infants with respiratory distress born to GDM mothers were unrelated to surfactant deficiency. ${ }^{25,26}$ Neonates of the mothers with GDM experiences respiratory distress syndrome even if they are term. ${ }^{27,28}$ Respiratory distress due to TTN is most common in term GDM neonates. TTN is more common in elective caesarean section due to lack of exposure to uterine contractions. ${ }^{29}$

\section{Hyperbilirubinemia}

It occurs due to the increased production and decreased life span of RBC's with glycosylated cell membranes. ${ }^{30}$ Women with normal fasting and elevated postprandial blood sugar values are having the infants at increased risk of hyperbilirubinemia. ${ }^{31}$ It is found with increased frequency in macrosomic infants of GDM mothers. ${ }^{32}$ Neonates with elevated bilirubin are treated with phototherapy. ${ }^{33}$

\section{Polycythaemia}

Polycythaemia is defined as peripheral venous haematocrit is $\geq 65 \%$. It occurs due to hypoxic stimulus by the placental insufficiency and elevated glycohemoglobin. ${ }^{34}$ The resultant hyper viscosity may induce congestive cardiac failure and vascular thrombosis. Polycythaemia is observed more frequently in infants of GDM mothers. Large for gestational age 
infants are at greater risk for polycythaemia in the early neonatal period. ${ }^{35}$

\section{Intrauterine death/ still birth}

Usually occurs after $36^{\text {th }}$ week of gestation in gestational diabetes. ${ }^{36,37}$ Causes are chronic intrauterine hypoxia with acidosis, high fasting blood sugar levels, placental dysfunction and competition for essential nutrients. ${ }^{38,39}$ Women with gestational diabetes are in high-risk category for foetal death. Therefore intensive monitoring is essential with the consideration for timed delivery. ${ }^{40}$

\section{Early pregnancy loss}

Early spontaneous pregnancy loss is more common in women with hyperglycaemia in periconceptional period and in the first trimester. ${ }^{41}$ More common in diabetes complicating pregnancy with poor blood sugar control.

\section{Preterm birth}

Preterm delivery may be either spontaneous or iatrogenic done for some maternal or foetal indications. It occurs more common in women with type 1 diabetes mellitus. Spontaneous preterm labor or premature rupture of membranes are due to poor blood glucose control. ${ }^{42}$

\section{Congenital anomalies}

The incidence of congenital anomalies is more common in overt diabetes. The abnormalities arise as a consequence of poor glycaemic control periconceptionally and during embryogenesis. ${ }^{32}$ Incidence of congenital malformation is $5-10 \% .{ }^{43}$ The most frequent anomaly involves the heart and CNS. Anomalies are more common in overt diabetes.

\section{ACKNOWLEDGMENTS}

All the GDM patients who participated in the study.

Funding: No funding sources

Conflict of interest: None declared

Ethical approval: The study was approved by the Institutional Ethics Committee, MMC, Chennai

\section{REFERENCES}

1. American Diabetes Association. Gestational Diabetes Mellitus. Diabetes Care. 2004;27:88- 90.

2. Sermer M, Naylor CD, Gare DJ, Kenshole AB, Ritchie JW, Farine D, et al. Impact of increasing carbohydrate intolerance on maternal- fetal outcome in 3637 women without gestational diabetes. The Toronto Ti- Hospital Gestational Diabetes Project. Am J Obstet Gynecol. 1995;173(1):146-56.

3. Seshiah V, Cynthia A, Balaji V, Balaji MS, Ashalata $\mathrm{S}$, Sheela R, et al. Detection and Care of women with gestational diabetes mellitus from early weeks of pregnancy results in birth weight of newborn babies appropriate for gestational age. Diab Res Clin Pract. 2008;80(2):199-202.

4. Bartha JL, Martinez-Del-Fresno P, Comino-Delgado R. Early diagnosis of gestational diabetes and prevention of diabetes related complications. Eurr J Obstet Gynecol Reprod Biol. 2003;109(1):41-4.

5. Anjalakshi C, Balaji V, Balaji MS, Ashalata S, Suganthi S, Seshiah V et al. A single test procedure to diagnose gestational diabetes mellitus. Acta Diabetol. 2009;46(1):51-4.

6. Balaji V, Balaji MS, Seshiah V, Mukundan S, Datta M. Maternal glycemia and neonatal birthweight in asian women. Diabetes Res Clin Prac. 2006;73(2):223-4.

7. Seshiah V, Balaji V, Balaji MS, Paneerselvam A, Arthi T, Thamizharasi M, et al. Gestational Diabetes Mellitus manifests in all trimesters of pregnancy. Diabetes Res Clin Pract. 2007;77(3):482-4.

8. Kim C, Berger DK, Charmany S. Recurrence of gestational diabetes mellitus. Diabetes Care. 2007;30(5):1314-9.

9. Yogev Y, Xenakis EM, Langer O. The association between preeclampsia and the severity of gestational diabetes:the impact of glycemic control. Am J Obstet Gynecol. 2004;191(5):1655-60.

10. Balaji V, Balaji MS, Seshiah V, Mukundan S, Datta M. Maternal glycemia and neonatal birthweight in asian women. Diabetes Res Clin Prac. 2006;73(2):223-4.

11. Evers IM, de Valk HW, Visser GH. Risk of complications of pregnancy in women with diabetes: nationwide prospective study in Netherlands. BMJ. 2004;328:915-9.

12. Kalra P, Kachhwaha CP, Singh HV. Prevalence of geatational diabetes mellitus and its outcome in western Rajasthan. Indian J Endocrinol Metab. 2013;17(4):677-80.

13. Seshiah V, Balaji V, Balaji MS, Aruna S, Sanjeevi $\mathrm{CB}$, Green A. One step screeningprocedure for screening and diagnosis of gestational diabetes mellitus. J Obstet Gynecol Ind Ded 2005;55(6):5259.

14. Pedersen J. Pathogenesis of the characteristic features of newborn infants of diabetic women, Williams and Wilkins. 1967:128-37.

15. Mitanchez D. Fetal and neonatal complications of gestational diabetes. J Gynecol Obstet Biol Reprod (Paris) 2010;39(8 Suppl 2):S189-99.

16. Mathew M, Machado L, Al- Ghabshi R, Al- Haddabi R. Fetal macrosomia. Risk factor and outcome. Saudi Med J. 2005;26(1):96- 100.

17. Oral E, Cagdas A, Gezer A, Kaleli S, Aydinli K, Ocer F. Perinatal and maternal outcomes of fetal macrosomia. Eur J Obstet Gynecol Reprod Biol. 2001;99(2):167-71.

18. Word play MP, Hawdon JM, Hypoglycemia in the neonate. In Gregory JW, Aynsley-Green A, Landon and Bailier Tindall; 1993:669-682 
19. Al- Khalifah R, AL-Subaihin A, Al- Kharfi T, AlAlaiyan S, Khalid MA. Neonatal Short- Term Outcomes of Gestational Diabetes Mellitus. J Clinic Neonatol. 2012;1(1):29-33.

20. Agarwal RK, Lui K, Gupta JM. Neonatal hypoglycemia in infants of diabetic mothers. J Paediatr Child Health. 2000;36(4):354-6

21. Cornblath M, Hawdon JM, Williams AF, et al. Controversies regarding definition of neonatal hypoglycemia:suggested operational thresholds. Pediatrics. 2000;105(5):1141-5.

22. Person B, Hanson U. Neonatal morbidities in gestational diabetes mellitus. Diabetic Care. 1998;21(2):79-84.

23. Jimenez- Moleaon JJ, Bueno- Cavanillas A, Lunadel-Castillo Jde D, Garcia- Martin M, Lardelli-Claret P, Galvez- Vargas R. Impact of different levels of carbohydrate intolerance on neonatal outcomes classically associated with gestational diabetes mellitus. Eur J Obstet Gynecol Reprod Biol. 2002;102(1):36-41.

24. Potter CF, Rosenkrantz T. Infant of diabetic mother. 2013. Available at http://emedicine.medscape.com/article/974230overview

25. Kios SL, Walther FJ, Montoro M, Paul RH, Diaz F, $\mathrm{S}$ tabler M. Prevalence and etiology of respiratory distress in infants of diabetic mothers: Predictive value of fetal lung maturation tests. Am J Obstet Gynecol. 1990:163(3):898-903.

26. Dornhorst A, Paterson CM, Nicholls JS, Wadsworth J, Chiu DC, Elkeles RS et al. High prevalence of GDM in women from ethnic minority groups. Diab Med. 1992;9(9):820-5.

27. Mayo Foundation for Medical Education and Research. 1998-2013. Available at https://prezi.com/xq9f4ckb6ynx/1998-2013-mayofoundation-for-medical-education-and-research/

28. Hermansen CL, Lorah KN. Respiratory distress in the newborn. Am fam physician. 2007:76(7):987-94.

29. Tutdibi E, Gries K, Buchler M, Misselwitz B, Schlosser RL, Gortner L. So Impact of labor on outcomes in transient tachpnea of the newborn:Pediatrics. 2010;125(3):577.

30. Perkins JM, Dun JP, Jagasia SM. Perspectives in gestational diabetes mellitus: a review of screening, diagnosis, and treatment. Clin Diab. 2007;25(2):5762.

31. Black MH, Sacks DA, Xiang AH, Lawrence JM. Clinical outcomes of pregnancies complicated by mild gestational diabetes mellitus differ by combinations of abnormal oral glucose tolerance test values. Diabetes Care. 2010;33(12):2524-30.
32. Opara PI, Jaja T, Uche CO. Morbidity and mortality amongst infants of diabetic mothers. Italian $\mathbf{J}$ Pediatrics 2010;36:77.

33. Gasim T. Gestational diabetes mellitus: maternal and perinatal outcomes. Oman Med J. 2012;27(2):140-4.

34. Tyrala EE. The infant of the diabetic mother. Obstetr Gynecol Clin North Am. 1996;23:221-41

35. Onal EE, Hirfanoglu IM, Beken S, Altuntas N, Turkyilmaz C, Camurdan AD et al. Are the neonatal outcomes similar in large for gestational age infants delivered by women with or without gestational diabetes. World J Pediatri 2012;8(2):136-9.

36. Patel PK. Profile of fetal deaths in dhahira region, Oman. Oman Med J. 2008 Jan;23(1):28.

37. Odar E, Wandabwa J, Kiondo P. Maternal and fetal outcome of gestational diabetes mellitus. Afr Health Sci. 2004;4(1):9-14

38. Bradley RJ, Brudenell JM, Nicolaides KH. Fetal acidosis and hyperlactinemia diagnosed by cardiocentesis in pregnancies complicated by maternal diabetes mellitus. Diabet Med. 1991;8:4648.

39. Girz BA, Diyon MY, Merkatz IR. Sudden fetal death in women with well- controlled, intensively monitored gestational diabetes. Perinatology. 1992;12(3):229-33.

40. Casson IF, Clarke CA, Howard CV, O McKendrick, POD Pharoah, S Walkinshaw - Outcome of pregnancy in insulin dependent diabetic women: results of a five year population cohort study. BMJ. 1997;315:275-8.

41. Mimouni F, Miodovnik M, Siddiqi TA, Berk MA, Wittekind C, Tsang RC. High spontaneous premature rupture labor in insulin dependent diabetic pregnant women: an association with poor glycemic control and urogenital infection. Obstet Gynecol. 1988;72:175-80.

42. Ray JG, O'Brien TE, Chan WS. Preconceptional care and the risk of congenital anomalies in the offspring of women with diabetes mellitus: a meta- analysis. QJM. 2010;94:435-44.

43. Janssen PA, Rothman I, Schwartz SM. Congenital malformations in newborns of women with established and gestational diabetes. Pediatr Perinatal Epidemiol. 1996;10(1):52-63.

Cite this article as: Kanmani K, Subramanian S. Perinatal outcome in relation to maternal glycaemic control in gestational diabetes mellitus. Int J Reprod Contracept Obstet Gynecol 2017;6:4618-24. 